\title{
Ingrid A.R. de Smet, Contre les cloches: pour une lecture de neuf épigrammes inédites de Jacques-Auguste de Thou (1553-1617)
}

\section{Filippo Fonio}

\section{(2) OpenEdition \\ Journals}

\section{Edizione digitale}

URL: http://journals.openedition.org/studifrancesi/35963

DOI: $10.4000 /$ studifrancesi.35963

ISSN: 2421-5856

\section{Editore}

Rosenberg \& Sellier

\section{Edizione cartacea}

Data di pubblicazione: 1 juillet 2005

Paginazione: 151

ISSN: 0039-2944

\section{Notizia bibliografica digitale}

Filippo Fonio, «Ingrid A.R. de Smet, Contre les cloches: pour une lecture de neuf épigrammes inédites de Jacques-Auguste de Thou (1553-1617)», Studi Francesi [Online], 145 (XLIX | I) | 2005, online dal 30 novembre 2015, consultato il 20 avril 2021. URL: http://journals.openedition.org/studifrancesi/35963 : DOI: https://doi.org/10.4000/studifrancesi.35963

Questo documento è stato generato automaticamente il 20 avril 2021.

\section{cc) $(9)$}

Studi Francesi è distribuita con Licenza Creative Commons Attribuzione - Non commerciale - Non opere derivate 4.0 Internazionale. 


\title{
Ingrid A.R. de Smet, Contre les cloches: pour une lecture de neuf épigrammes inédites de Jacques- Auguste de Thou (1553-1617)
}

\author{
Filippo Fonio
}

\section{NOTIZIA}

INGRID A.R. DE SMET, Contre les cloches: pour une lecture de neuf épigrammes inédites de JacquesAuguste de Thou (1553-1617), «Bibliothèque d'Humanisme et Renaissance», LXVI, 1 (2004), pp. 91-110.

1 Si tratta dell'edizione critica con traduzione di nove epigrammi latini di JacquesAuguste de Thou dal ms. Dupuy 460 della Bibliothèque nationale, preceduta da una valutazione letteraria e da un tentativo di interpretazione delle liriche. La serie epigrammatica, che dal titolo apposto alla prima composizione può essere denominata EIS KWDWNAS (Contre les cloches), è appunto incentrata sulla tematica delle campane e del fastidio da esse arrecato al lavoro del poeta. Circa la datazione degli epigrammi, essi possono situarsi fra la metà degli anni Ottanta del XVI sec. e il 1594. Alla successione delineata dallo sviluppo dell'argomento si accompagna la coerenza metrica (le composizioni I e IX sono in trimetri giambici, le altre in distici elegiaci), che contribuisce a conferire alle liriche il senso di una serie che si apre e si chiude. La tematica delle cloches - oltre alla principale forma di inquinamento acustico nelle città pre-industriali, e a un locus satirico da Giovenale in poi - non può non ricondursi all'attualità politica della querelle des cloches nella Francia della seconda metà del Cinquecento, come del resto avviene in altre opere letterarie coeve, fra cui il Cinquiesme livre di Rabelais - in merito a ciò cfr. in part. MICHEL SIMONIN, L'édition de l'Isle sonnante (1562-1563), in Le Cinquiesme Livre. Actes du colloque international de Rome (16-19 
octobre 1998), a cura di FRANCO GIACONE. Etudes rabelaisiennes, Tome XL, Genève, Droz («Travaux d'Humanisme et Renaissance», CCCLIV), 2001, pp. 55-66. Il lessico degli epigrammi di de Thou è conservativo e si richiama per lo più al latino classico, prediligendo inoltre all'utilizzo di forme tardo-latine o umanistiche il conio di neologismi su radici classiche. Il modello ricorrente, specie nei primi componimenti della serie, è Catullo. 